\title{
De la verdadera religión a la verdad de la religión: el giro soteriológico en la teología de las religiones
}

\author{
Joaquín Silva \\ FACULTAD DE TEOLOGÍA \\ PONTIFICIA UNIVERSIDAD CATÓLICA DE CHILE \\ jsilvas@uc.cl
}

\section{INTRODUCCIÓN}

La religión ha vuelto a ser un tema de interés no solo para las grandes religiones, sino que también para los Estados y, por cierto, para las mismas personas. La internacionalización de los mercados y los medios de comunicación social han contribuido a un nexo mucho más intenso y profundo entre los pueblos y las culturas. Las migraciones por razones políticas, militares o económicas han llevado a cientos de miles de personas a cruzar las fronteras y a creer "en tierra extraña” (Sal 137, 4). Los pueblos que han recibido a los migrantes, por su parte, han debido respetar la libertad religiosa de quienes llegan al país, no solo posibilitando la adhesión a convicciones religiosas distintas a las del propio país, sino que también generando las condiciones para que ellas se desarrollen tanto teórica como prácticamente ${ }^{1}$. En los conflictos nacionales e internacionales se ha reconocido un fuerte componente religioso, que también ha llevado a preguntarse por el rol que pudiera estar jugando la religión en ellos: sea como un factor que se hace presente activa y protagónicamente, sea como un recurso ideológico para encubrir intereses muy distintos a los de la propia religión. Las situaciones de injusticia y pobreza siguen lacerando a la humanidad y plantean serios interrogantes a nuestros modelos de desarrollo, a la justicia y a la paz. Las religio-

\footnotetext{
En Alemania, por ejemplo, donde viven cuatro millones de musulmanes, el Ministerio de Educación e Investigación (BMBF) ha erigido cuatro Centros de Teología Islámica: en Münster/Osnabrück, Tübingen, Frankfurt/Gießen y en Nürnberg-Erlangen.
} 
nes pudieran ser indiferentes ante el hecho, legitimarlo religiosamente o bien ser un factor de cambio y transformación social, un aporte efectivo a una sociedad más digna para todos.

La teología se ocupa de la religión porque en sus diversas formas históricas se expresa y realiza el encuentro entre Dios y el hombre, porque incluso allí donde parece ser negada u olvidada, ella emerge como una respuesta a los anhelos más hondos de los hombres, como una posibilidad de saciar las búsquedas de un sentido trascendente y absoluto, como la superación de la finitud y de la muerte que lo amenaza todo ${ }^{2}$. Es por esto que la pregunta por las religiones, "hasta ahora demasiado teórica y académica -como afirma A. Gesché- se ha convertido en una cuestión cultural. Estamos ante un problema de civilización, en donde las antiguas respuestas, sean las que fueren, se muestran vacilantes o resultan inadaptadas" 3 . El concepto de "teología de las religiones" es de reciente data y surge, precisamente, de un interés por abordar la cuestión de la religión no de modo abstracto, sino "en su realidad histórica y condiciones concretas" $"$.

Si quisiéramos rastrear las "teologías de las religiones" anteriores al Vaticano II deberíamos remitirnos a la misma práctica de Jesús y a sus enseñanzas, como asimismo a sus antecedentes especialmente en la literatura profética. En efecto, es muy difícil comprender a Jesús de Nazareth al margen de la pregunta por la verdad del culto (Jn 4, 2 3; Rom 12, 1), de la oración (Mt 6, 5), de la limosna $($ Mt 6, 2), de la doctrina (Mt 15, 12. 19; Mc 8, 38), de determinadas prácticas éticas (Lc 11, 46); en definitiva, al margen de la pregunta por el verdadero Dios, pregunta decisiva de cualquier teología de la religión (Mt 11, 27; Lc 10, 22). Es así, por ejemplo, que Santiago puede luego afirmar que "la religión pura y sin mancha delante de nuestro Dios y Padre es esta: visitar a los

2 Cf. NA 1; K. H. OHLIG, La evolución de la conciencia religiosa. La religión en la historia de la humanidad (Herder, Barcelona 2004) 15-28.; B. WeLTE, «Christentum und Religionen der Welt», en F. BöCKLE (dir.), Christlicher Glaube in moderner Gesellschaft, XXVI (Herder, Freiburg - Basel - Wien 1980) 45-46.

3 A. Gesché, El destino: Dios para pensar III (Sígueme, Salamanca 1995) 148.

4 M. Seckler, «Der theologische Begriff der Religion», en W. Kern - H. J. PotTMEYER - M. SECKLER (dirs.), Handbuch der Fundamentaltheologie (Francke, Tübingen - Basel 2000) 132. Según M.Seckler, el primero en proponer esta teología fue H.R.Schlette, el año 1963, al publicar su obra Die Religionen als Thema der Theologie. Überlegungen zu einer "Theologie der Religionen" (loc.cit). 
huérfanos y a las viudas en sus aflicciones, y guardarse sin mancha del mundo" (St 1, 27) $)^{5}$.

Sin embargo, a nuestro juicio, muy tempranamente se produjo un desplazamiento de la pregunta por la verdad de la religión a la pregunta por la verdadera religión. De este modo, dejó de estar al centro de la preocupación teológica la crítica profética de las teorías y prácticas religiosas que encubren el auténtico rostro de Dios y, hasta el día de hoy, el interés se ha puesto, principalmente, en determinar apologéticamente si aquellos que pertenecen a otras religiones se podrán salvar o no ${ }^{6}$.

Este desplazamiento del interés teológico tiene, a nuestro entender, solo una apariencia de soteriología: se habla de salvación, incluso se quiere incluir a todos en ella; sin embargo, lo que rige el interés de esta teología es -propiamente- la religión o, si se quiere, las religiones; el foco ha dejado de ser -como en Jesús- la transformación del mundo y de las relaciones entre los hombres, según el querer de Dios. Como explica P. Gisel, la teología de la religión -justamente en su pretensión de ser teología- no puede constituirse en un discurso introvertido sobre la Iglesia, sobre el cristianismo o sobre la religión. En cuanto referido a Dios, el discurso teológico aspira a una comprensión de la totalidad de la existencia humana y del mundo, preguntando por las condiciones y posibilidades de la experiencia de salvación en el acontecer de la historia ${ }^{7}$.

Para el desarrollo de nuestras reflexiones, el giro soteriológico del Concilio Vaticano ${ }^{8}$ será considerado como un punto de partida, como un hito en el camino, como una invitación a seguir pensando en virtud de las cuestiones que él mismo planteó. En definitiva, nuestras reflexiones están más en línea con la recepción de los documentos del Vaticano II que con su génesis y formulación.

5 Cf. W. RadL, «Threskeia», in Exegetisches Wörterbuch zum Neuen Testament (Kohlhammer, Stuttgart - Berlin - Köln 1981) 382-384.

6 Cf. R. Bernhardt, La pretensión de absolutez del cristianismo. Desde la ilustración hasta la teología pluralista de la religión (Desclée de Brouwer, Bilbao); C. SCHUBERT, Ad veram religionem reformare: frühchristliche Apologetik zwischen Anspruch und Wirklichkeit (Universitätsbund Erlangen-Nürnberg e.V, Erlangen).

7 Cf. P. Gisel, La théologie face aux sciences religieuses (Labor et Fides, Geneve) 278 y ss.; P. Gisel, La théologie (Quadrige manuels . Philosophie, Presses universitaires de France, Paris 2007) 123 y ss.

8 Por ejemplo: LG 14, GS 22 o NA 2. 
Principales aCENTOS EN LA TEOlogía de LAS RELIGIONES DESPUÉS DEL VATICANO II

La caracterización más común de las diferentes teologías de la religión se ha hecho en base a tres modelos principales: el exclusivista, el inclusivistas y el pluralista, los que tienen un correlato en la distinción entre eclesiocentrismo, cristocentrismo y teocentrismo? . Como explica M. Dhavamony, estos modelos o aproximaciones a la religión son "aproximaciones que han sido propuestas para resolver la tensión entre dos axiomas fundamentales: a) que la salvación es solo a través de Jesucristo; b) que Dios desea la salvación de toda la humanidad ${ }^{10}$. Según sea el acento que se ponga en uno u otro axioma, en la relación intrínseca entre ambos o en la negación de alguno de ellos, la comprensión soteriológica será más o menos inclusiva y plural, más o menos universal.

En la perspectiva de una teología de la religión exclusivista, solo en el cristianismo se encuentra la salvación y todas las demás religiones son falsas. Como botón de muestra de esta mirada de las cosas podemos recordar el Concilio de Florencia, que citando textos de Fulgencio de Ruspe (468-533) declara: "firmemente creer, profesar y enseñar que ninguno de aquellos que se encuentran fuera de la Iglesia Católica, no solo los paganos, sino también los judíos, los herejes y los cismáticos, podrán participar en la vida eterna. Irán al fuego eterno que ha sido preparado para el diablo y sus ángeles (Mt 25, 41), a no ser que antes de su muerte se uniere con ella [...] Y que nadie, por más limosnas que hiciere, aun cuando derramare su sangre por el nombre de Cristo, puede salvarse, si no permaneciere en el seno y unidad de la Iglesia Católica” (DH 1351).

9 Según Schreiter esta distinción tripartita tiene su origen en el teólogo británico Alan Race, en su libro Christians and religious pluralism. Patterns in the Christian theology of religions (Maryknoll 1982). Cf. R. SCHreITER, "Hindernisse und Leitlinien für die Mission und den Dialog mit den Religionen», en P. HünERMAnN (dir.), Das zweite Vatikanische Konzil und die Zeichen der Zeit heute (Herder, Freiburg Basel - Wien 2006) 448.

10 R. Bernhardt, La pretensión de absolutez del cristianismo. Desde la ilustración hasta la teología pluralista de la religión; M. DHAVAMONY, "Religión: Teología de las religiones», en R. Latourelle - R. Fisichella - S. Pié-Ninot (dirs.), Diccionario de Teología Fundamental (San Pablo, Madrid 1992) 1220; J. Dupuis, Jesucristo al encuentro de las religiones (Paulinas, Madrid); H. Kesslen, "Pluralistiche Religionstheologie und Christologie. Thesen und Fragen", en R. Schwager (dir), Christus allein? Der Streit um die pluralistiche Religionstheologie (Herder, Freiburg - Basel - Wien 1996) 158-173. 
Más matizadamente, el gran teólogo protestante K. Barth dedica un capítulo de su Kirchliche Dogmatik a la "Revelación de Dios como abolición de la religión”, por considerar a esta como un vano intento del hombre por adquirir dominio y poder sobre Dios, a través de la práctica cultual, moral e incluso teórica. Como es sabido, para Barth Dios no es objeto del pensamiento teológico (vía positiva) ni tampoco aquello que no pueda ser pensado (via negativa), sino el misterio que se revela en Cristo incondicionadamente. Aquí el exclusivismo no toma la forma del eclesiocentrismo, sino de la "sola fe, sola gracia, sola Escritura", fuera de las cuales no hay salvación ${ }^{11}$.

Contra este exclusivismo eclesiocéntrico, el giro soteriológico permite establecer un hecho teológico mayor: los seguidores de otras religiones pueden recibir la gracia de Dios y ser salvados por Cristo independientemente de los medios ordinarios que él ha establecido (cf. GS 22, NA 2; RM: 55). Esta es la afirmación dogmática principal, el enunciado primero, la constatación fundante de cualquiera otra enseñanza. La gracia y la salvación nos han sido dadas por Dios en Cristo, y pueden acontecer en la historia independientemente de los medios ordinarios que el mismo Cristo ha establecido. La Iglesia no es necesaria como lo es Dios, o la salvación; la Iglesia es necesaria como un signo o instrumento de esa salvación universal. Ella ha sido constituida, justamente, para testimoniar que el reinado de Dios ha irrumpido en la historia como gracia que desborda y supera toda segregación entre los hombres. Por la gracia de Dios en Cristo, y que nos ha sido regalada por el don del Espíritu Santo, ahora todos los hombres y todos los pueblos pueden participar de la salvación de Dios; eso es Pentecostés; y ese es el kerigma (cf. Hech 2).

Desde un punto de vista dogmático pareciera hoy muy difícil sustentar un eclesiocentrismo exclusivista, apelando a la tradicional expresión «extra ecclesiam nulla salus». Como lo recuerda la misma LG 16, ya en 1949 el Santo Oficio había refutado las interpretaciones rigoristas de este axioma, que hacían miembros del St Benedict's Center y del Boston College (cf. DH 3866-3873). Tanto LG 16, GS 22, como NA 2 representan una clara superación de dicho exclusivismo y reconocen la posibilidad de salvación para quienes no pertenecen visiblemente a la Iglesia Católica. Esta afirmación ha llevado a comprender la necesidad

11 J. M. VigiL, Teología del pluralismo religioso. Curso sistemático de teología popular (Editorial Abya Yala, Quito 2005) 62. 
de la Iglesia para la salvación (cf. LG 14 y 48), según un modelo inclusivista y concéntrico ${ }^{12}$ que, en definitiva, devuelve al concepto de Iglesia su sentido teológico más radical: ser expresión histórica de la comunión de los hombres con Dios y de la comunión de todo el género humano.

En la perspectiva de Mt 25, LG enseña que el único criterio decisivo de pertenencia a la Iglesia es la caridad. Al final del tiempo se podrá manifestar que, quizás, muchos de los que estaban plenamente incorporados a la Iglesia por la gracia y por los tres elementos visibles de la unidad católica (la profesión de fe, los sacramentos y las estructuras jerárquicas) ahora no participarán de la gloria de Cristo: "No se salva -dice el Concilio- aunque esté incorporado a la Iglesia, quien no perseverando en la caridad, permanece en el seno de la Iglesia «en cuerpo», mas no «en corazón» (LG 14). Y, por el contrario, se podrán salvar todos aquellos hombres y mujeres que incluso no habiendo llegado a un conocimiento expreso de Dios, "se esfuerzan en llevar una vida recta, no sin la gracia de Dios. Cuanto hay de bueno y verdadero entre ellos, la Iglesia lo juzga como una preparación del Evangelio y otorgado por quien ilumina a todos los hombres para que al fin tengan la vida" (LG 16).

Obviamente, el eclesiocentrismo exclusivista no es solo un problema teórico-dogmático. Desde un punto de vista dogmático, como vimos, se puede decir que ya está zanjado. Pero teóricamente resuelto no implica prácticamente resuelto. En la vida pastoral, en la espiritualidad, en los lenguajes cotidianos, en las prácticas institucionales, etc., nos parece que todavía estamos lejos de ser Iglesia según los criterios de la comunión y de la caridad. La misma sociedad nos percibe más como una institución preocupada de justificarse, reproducirse, sanearse..., que de hacer el bien y buscar la verdad junto a todos los hombres y mujeres de buena voluntad. ¿De qué modo expresamos histórica y visiblemente esa concentridad del ser Iglesia que propone LG? ¿No seguimos comprendiendo la Iglesia, principalmente, desde una perspectiva sociológica, jurídica, institucional, para justamente acentuar cada vez más los límites y fronteras que nos diferencian de los demás? ¿Por qué nos cuesta tanto mirar teológicamente la Iglesia: desde Dios, de su designio universal de salvación, desde su radical sí a todo lo bueno, verdadero y bello que hay entre los hombres y en todos los pueblos?

12 R. Polanco, "La Iglesia y la universalidad de la salvación en el cristianismo», Teología y Vida 44 (2003) 423-443. 
Por su parte, el modelo cristocéntrico inclusivista reconoce la posibilidad de la salvación en las demás religiones, pero se les niega a estas una autonomía salvífica en razón de la unicidad y la universalidad de la salvación de Jesucristo. Esta postura, que pareciera ser la más común entre los teólogos católicos, "procura conciliar la voluntad salvífica universal de Dios con el hecho de que todo hombre se realiza como tal dentro de una tradición cultural, que tiene en la religión respectiva su expresión más elevada y su fundamentación última"13. La particularidad espaciotemporal del acontecimiento de Cristo es la condición de posibilidad de su realización histórico-escatológica, es allí donde radica el sentido y alcance universal de acontecimiento. En Cristo, el "universal" no solo se vuelve "particular", sino que también "personal"14. Este carácter personal de la salvación de Dios en Cristo es la que permite a todo hombre y mujer participar de la amistad de Dios en todo tiempo y lugar, según las condiciones de cada cultura. Es en Cristo, por quien todo fue hecho, en quien también todo alcanza su consistencia y plenitud (Ef 1, 23).

La Iglesia de Cristo, en tanto Cuerpo de Cristo (cf. 1 Cor 12, 27; Col 1, 24; Ef 5, 30), no es solo la realización histórico-escatológica del universal-concreto-personal, sino que en ella la salvación se hace también social y comunitaria. En Cristo hemos sido hechos hijos en el Hijo; y, como explica Pablo, la Iglesia ha sido constituida en testimonio vivo del cumplimiento de las promesas que Dios había hecho por medio de sus profetas: "A los que no eran mi pueblo, llamaré: «Pueblo mío». Y a la que no era amada: "amada mía». Y sucederá que en lugar donde se les dijo: "Ustedes no son mi pueblo», allí serán llamados Hijos del Dios viviente" (Rom 9, 25). Por la gracia y la fe hemos sido constituidos en descendientes de Abraham, en destinatarios de las promesas, en la comunidad de los santos de Dios (Gal 3, 7; 4, 5). Y porque hemos sido hechos hijos, "Dios ha enviado el Espíritu de Su Hijo a nuestros corazones, clamando: “AAbba! ¡Padre!” (Gal 4, 6).

Efectivamente, como lo ha planteado la Declaración Dominus Iesus de la Congregación para la Doctrina de la Fe no es posible "introducir una separación entre la acción salvífica del Logos en cuanto tal, y la del Verbo hecho carne. Con la encarnación, todas las acciones salvíficas del

13 Comisión Teológica Internacional, "El cristianismo y las religiones», 1996.

14 Cf. S. Pié-Ninot, La teología fundamental. "Dar razón de la esperanza" (1 Pe 3, 1 5) (Secretariado Trinitario, Salamanca) 274-297. 
Verbo de Dios, se hacen siempre en unión con la naturaleza humana que él ha asumido para la salvación de todos los hombres. El único sujeto que obra en las dos naturalezas, divina y humana, es la única persona del Verbo. Por lo tanto no es compatible con la doctrina de la Iglesia la teoría que atribuye una actividad salvífica al Logos como tal en su divinidad, que se ejercitaría "más allá» de la humanidad de Cristo, también después de la encarnación" (n.10). Sin embargo, como ha notado A. Bentué, esta "inseparabilidad no puede comprenderse de tal manera que se excluyan las otras religiones, sino incluyéndolas como formas plurales, en la que puede estar presente «de una manera invisible [...] y conocida por Dios» (GS 22), a lo menos como iglesia implícita, la única Gracia de Dios dada a todos los hombres, en el único Salvador Jesucristo, y transmitida explícitamente en la única Iglesia histórica”"15.

No nos cabe duda de la pertinencia de este modelo "cristológicoinclusivista”. En él efectivamente se reconoce la posibilidad de salvación en las demás religiones, en virtud del alcance universal del acontecimiento histórico-escatológico de Cristo. Hay un claro desplazamiento de la salvación desde la Iglesia a Cristo, se reconoce la universalidad inclusiva de este acontecimiento particular-personal, y desde él se aprecia el significado de la Iglesia.

Sin embargo, pensamos que este modelo tampoco expresa suficientemente el giro soteriológico expresado en el Vaticano II. La vida y la acción histórica de los hombres, los esfuerzos cotidianos de hombres y mujeres por construir una sociedad más justa, todo aquello que durante los siglos las culturas y los pueblos han sembrado bajo el signo de la corrupción y la muerte (GS 39) no es reconocido en su valor intrínseco, como realización histórica de la salvación. La preocupación, en este modelo también, siguen siendo Cristo y la Iglesia. Las experiencias de vida y libertad, de justicia y de paz, de fraternidad y comunión no son apreciadas en su consistencia ontológica. Y, por ello mismo, apenas alcanzan densidad salvífica ${ }^{16}$.

15 A. BENTUÉ, Jesucristo en el pluralismo religioso: un único salvador universal (Eds. Universidad Alberto Hurtado, Santiago, Chile 2012) 29.

16 En el sentido de la afirmación de Jesús "El Padre es mayor que yo" (Jn 14, 28), habría que considerar que "incluso en la religión de la encarnación de Dios, Jesús no deja de recordar que es hacia el Padre, no hacia él, hacia donde hemos de volvernos, para encontrar precisamente allí la separación y la mediación que salvan de la inmediatez. Puede haber en nuestra teología, como tantas veces nos recordó 
En este modelo, Dios es aquella realidad trascendente que supera toda representación de las religiones y que ha tenido diversos testimonios en las culturas, sin que ninguno de ellos se pueda arrogar algún tipo de privilegio, exclusividad o absolutez. Por tanto, Cristo puede ser un testigo más o menos normativo, según haya una comunidad de creyentes que quieran vivir según sus enseñanzas, pero no según una verdad universal construida a partir de esas mismas creencias y prácticas religiosas. El conocimiento religioso y la verdad a la que ella accede poseen un carácter, "evolutivo, culturalmente condicionado, pragmático y caracterizado por su polaridad" 17 .

Esta perspectiva teocéntrica pluralista se radicalizaría en el "soteriocentrismo", el cual opera un desplazamiento del interés desde la cuestión sobre Cristo (ortodoxia) a la cuestión del compromiso efectivo de las religiones con el sufrimiento y dolor de la humanidad (ortopraxis). Así -afirma la Comisión Teológica Internacional- "el valor de las religiones está en promover el Reino, la salvación, el bienestar de la humanidad. Esta posición puede así caracterizarse como pragmática e inmanentista"18. En esta misma línea, A. Gesché expone críticamente esta perspectiva así: "como hoy se juzga cada vez más a una religión por el valor de su comportamiento y de la autenticidad de su práctica, y hasta por el éxito de sus resultados, la cuestión sobre su verdad tiende a resolverse, como ya lo sugería Spinoza, por el carácter moral de tal o cual religión, mientras que su bagaje doctrinal no tiene más valor que el de servir de apoyo o de referencia simbólica. Y el cristiano pensará incluso que tiene a su favor la lógica del Evangelio, que pide ser llevado a la práctica no solamente con palabras, sino (¿sobre todo?) con obras. Y hasta encontrará un apoyo en la filosofía que, al descubrir el carácter autoimplicativo del lenguaje religioso y la naturaleza existencial de sus posiciones, desplaza de alguna manera el juicio de la verdad hacia el sujeto y su sinceridad, antes que hacia el objeto o el contenido" 19 .

Yves Congar, un cristocentrismo que no es cristiano. Este es uno de los sentidos del secreto mesiánico. Al absolutizarse, el cristianismo cae en la idolatría, y esta falsificación se vuelve contra él y contra su lógica, que consiste precisamente en ser una lucha contra la idolatría para que la salvación no sea vana” A. GESCHÉ, El destino: Dios para pensar III, 212.

17 T. Merrigan, «El conocimiento religioso en la teología pluralista de las religiones», Selecciones de Teología 151 (1999) 231-240.

18 Comisión Teológica Internacional, «El cristianismo y las religiones», 16.

19 A. Gesché, El destino: Dios para pensar III, 187-188. 
Aunque el desplazamiento del eje teológico pudiera inducirnos a pensar que en estas teologías pluralistas de la religión se produce un real giro soteriológico, nuestra opinión es que ello no es así, que se trata más de una apariencia que de una realidad. En efecto, al separar ortodoxia de ortopraxis, esta queda desligada de su principio y fundamento. La pregunta por la acción correcta, buena o verdadera, no se resuelve por la sola práctica, sino que implica la pregunta también teórica por aquello que es bueno o verdadero, aunque - por cierto- esta pregunta no pueda sino ser respondida según la condiciones de cada tiempo y lugar. La experiencia religiosa, en concreto, nos remite a una conciencia que percibe la acción de Dios en la historia de los hombres, que considera que la vida de los hombres y especialmente su praxis importan a Dios, que la religión no es otra cosa que vivir la inmanencia en relación a la trascendencia ${ }^{20}$. Por tanto, para las religiones no será poco relevante pensar sobre las condiciones y posibilidades de la justicia y de la paz en Dios. La teología de las religiones no puede refugiarse en la acción por un mundo mejor, sin esclarecer qué sea ese mundo mejor y cómo ese mundo mejor tiene que ver con aquello que denomina Dios. Atender a esta pregunta no constituye una evasión de la responsabilidad ética que comporta la injusticia y la inequidad, sino que es asumir esta responsabilidad en Dios, en su fundamento, es reconocer su propia trascendencia.

Pero el giro soteriológico tampoco me parece claro en esta perspectiva teológica, por cuanto la práctica de la justicia y de la paz pueden convertirse fácilmente en un fetiche de la acción humana, capaz de encubrir cualquier intento de dominio y de poder. La referencia a Dios no solo permite reconocer la trascendencia de la praxis, sino que también ella se constituye en reserva crítica de todo intento por querer aprisionar lo infinito en la finitud de cualquier experiencia histórica, por más bella que ella sea. En toda religión, lo que llamamos "Dios" y su revelación permanecen como criterios normativos de la acción; y esta normatividad en lugar de inhibir la acción, le otorga una fuerza interior que la impulsa siempre a un bien mayor, a un justicia más plena, a una armonía más total.

\section{GIRO SOTERIOLÓGICO EN LA DINÁMICA DE LA CARIDAD}

En una auténtica religión pudieran faltar las palabras, pero nunca los hechos. Pensar soteriológicamente es reconocer que podemos llegar in-

20 Cf. N. Luhmann, La religión de la sociedad (Trotta, Madrid 2007) 67. 
cluso a no creer, pero que en la experiencia del amor al más necesitado allí habremos estado con Jesús. El giro soteriológico debe impulsar a la teología de las religiones a desplazar su mirada desde la pregunta por quién es el salvador, a la pregunta por el acontecer de la salvación en la historia de los hombres. Juan y sus discípulos querían saber si Jesús era el Mesías o si debían esperar a otro. Y Jesús no les responde; o, mejor dicho, les responde con una contundente afirmación soteriológica: "Los ciegos ven, los cojos andan, los leprosos quedan limpios, los sordos oyen, los muertos resucitan, se anuncia a los pobres la Buena Nueva" (Lc 7, 22b). ¿Demasiado pragmático, inmanente, histórico? Quizás por ello Jesús advierte inmediatamente: "y dichoso aquel que no halle escándalo en mí!” (Lc 7, 23). Para seguir con este mismo pasaje, la teología de las religiones debiera entonces articularse según el consejo de Jesús: "Id y contad lo que habéis visto y oído" (Lc 7, 22a). De este modo, la teología de las religiones se vuelve una teología de los signos de los tiempos, una teología de la historia, una teología de la presencia salvífica de Dios ${ }^{21}$.

Por cierto, la teología es un "logos”, pero logos de la acción salvífica de Dios en Cristo y en el Espíritu que, según sus promesas (Jl 3, 1-5), "en estos últimos días ha sido derramado sobre toda carne" (Hech 2, 17). Las palabras y los hechos de Jesús son correlativos y, en cuanto nos remiten a su persona, no se pueden disociar. Esta correlación, por ello, exige a la teología no solo estar atenta a las condiciones lógicas y formales de sus enunciados, sino que -principalmente- ser inteligencia agradecida de la acción salvífica de Dios en la historia.

El giro soteriológico no puede significar una negación de la particularidad en la que Dios ha querido que acontezca germinalmente su salvación universal, ni tampoco una negación de la comunidad que ha sido constituida como signo e instrumento de la unión con Dios y de todo el género humano. El giro soteriológico, más bien, lleva a pensar a Cristo y su Iglesia propter nostram salutem, desde la categoría de la proexistencia de Cristo (Barth, Schürmann) y, consecuentemente, de la comunidad de hombres y mujeres que llamó para estar con Él y enviarlos a anunciar

21 Cf. O. GonzÁlez de CARdedAl, El quehacer de la teología: génesis, estructura, misión (Verdad e imagen, Sígueme, Salamanca 2008, 271 y ss.; P. HÜNERMAnN, «La acción de Dios en la historia. Teología como interpretatio temporis», en J. O. BEOzzo - P. HÜnermann - C. SChickendantz (dirs.), Nuevas pobrezas e identidades emergentes: Signos de los tiempos en América Latina (Editorial de la Universidad Católica de Córdoba, Córdoba 2006) 17-59. 
su Evangelio ${ }^{22}$. Esta es la razón por la cual es inseparable Jesús del reino, Jesús de la vida plena de los hombres, Jesús de la comunidad que, por la fuerza de su Espíritu, ha dado testimonio y realizado históricamente su amor por los hombres. Jesús es el don de Dios a los hombres, es el Pan de Vida (Jn 6, 35), es la Palabra que se ha hecho carne (Jn 1, 14). No es posible hablar de Jesús y confesarlo como el Cristo despojándolo de su misión; sería negar su misma existencia, su ser para los demás; finalmente, sería también negar a Dios, su Padre.

La constitución Gaudium et Spes hace una lúcida y sugerente recepción de la categoría de sacramento aplicada a la Iglesia por Lumen Gentium, para afirmar que toda contribución a la unidad de los hombres y de los pueblos "concuerda con la misión íntima de la Iglesia” (GS 42). La propuesta de Nicolás de Cusa "religio una in rituum varietate" 23 no debe comprenderse como la nivelación de toda diferencia, sino que el efectivo encuentro de la diversidad en la unidad católica. En efecto, la unidad histórico-social "procede de la unión de los espíritus y de los corazones, esto es, de la fe y de la caridad, que constituyen el fundamento indisoluble de su unidad en el Espíritu Santo” (GS 42).

En este contexto el que el Concilio denuncia como "uno de los errores más graves de nuestra época el divorcio entre la fe y la vida” (GS 43), cuestión sobre la que ya Pío XI había llamado dramáticamente la atención el año 1937 en su Encíclica Mit brenneder Sorge (n. 17) y que luego tendrá significativas nuevas modulaciones, como en Pablo VI, quien afirmó que "la ruptura entre Evangelio y cultura es sin duda alguna el drama de nuestro tiempo" (EN 20); o en Puebla, donde los obispos denuncian la incoherencia entre la fe que decimos profesar y practicar y el compromiso real que asumimos en la sociedad, las contradicciones que implica el "divorcio entre fe y vida" (Puebla, 783).

Corresponde por tanto preguntar a las religiones por su real contribución al reconocimiento de los derechos de los más pobres, al aprecio de las culturas, al fomento de una vida más plena para todos. Esta pregunta, con un cargado énfasis ético, es a la vez la pregunta religiosa por excelencia: Dios vuelve a preguntar al hombre, ¿dónde está tu hermano? (Gen 4, 9).

22 Cf. O. GonzÁlez de Cardedal, La entraña del cristianismo (Secretariado Trinitario, Salamanca) 469.

23 De pace fidei, cap. 1. Citado por B. Welte, "Christentum und Religionen der Welt», 118. 
¿Soteriocentrismo pragmático e inmanentista? Se podría pensar que este giro soteriológico constituye un "soteriocentrismo" que, como se ha dicho, "tiene menos interés en la cuestión sobre Jesucristo (ortodoxia) y más en el compromiso efectivo de cada religión con la humanidad que sufre (ortopraxis)"24. Aunque la posibilidad de una comprensión pragmática e inmanente de la salvación pueda existir, aquí hemos querido insistir -más bien- en la necesaria relación y vínculo entre ortodoxia y ortopraxis. Pensamos que un auténtico interés por "la cuestión sobre Jesucristo" no puede separarse del "compromiso con la humanidad que sufre”. La afirmación de Jesús como el Cristo comporta necesaria, e ineludiblemente, el compromiso con el hermano que sufre, la colaboración con la instauración de la paz y la justicia. A Jesús no se le puede despojar de sus palabras ni de sus hechos. La verdad de la comunión con Él -y en Él con Dios-, no se produce por la reiteración de afirmación abstractas despojadas de todo sentido histórico-salvífico, sino que por el testimonio de aquel que pasó haciendo el bien (Hech 10, 38): “... lo que hemos visto y oído, os lo anunciamos, para que también vosotros estéis en comunión con nosotros. Y nosotros estamos en comunión con el Padre y con su Hijo Jesucristo" (1 Jn 1, 3). La comunión eclesial se sostiene en los hechos y palabras de Jesús, en el anuncio de quienes creyeron que en Jesús había irrumpido el reinado de Dios, la salvación definitiva, la fuente de toda alegría plena (cf. $1 \mathrm{Jn} 1,4)$.

"La cuestión de Jesús" es el reinado de Dios, es la comunión plena de los hombres con Dios y la comunión de los hombres entre sí. La Iglesia es constituida por Cristo para ser signo e instrumento de su propia causa, de aquello para lo cual vino al mundo (LG 1). Por ello, no puede haber ortodoxia sin ortopraxis, no puede haber preocupación por "la cuestión de Jesús" sin al mismo tiempo comprometerse "con la humanidad que sufre". El giro soteriológico, en definitiva, no es otra cosa que la conversión a la que Jesús conmina a sus oyentes, a fin de que su práctica no fuera hipócrita, sino que consecuente con la afirmación de Dios como Señor de la historia $(\mathrm{Mt} 7,21)$.

\section{El GIRO SOTERIOLÓGICO EN LA DINÁMICA DE UNA CONCIENCIA LIBRE}

El giro soteriológico comporta una auténtica afirmación de la autonomía del hombre. La clave hermenéutica fundamental es que hemos sido

24 Comisión TeOlógica Internacional, «El cristianismo y las religiones» 14. 
liberados para la libertad (Gal 5, 1). Es difícilmente representable, en la perspectiva del Evangelio, una salvación que para el hombre no implicara mayor plenitud, una existencia con más sentido, una afirmación de su propia consistencia ontológica. Para una teología de la religión esto implica afirmar que la salvación se ofrece al hombre y a la mujer como una posibilidad concreta de autorrealización en la libertad.

Sin embargo, es necesario preguntar: ¿dónde encuentra la libertad las posibilidades de su autorrealización?; ¿bajo qué condiciones la apelación a la libertad deja de ser un deseo abstracto e indeterminado?; ¿qué hace posible que la determinación de la libertad no sea un mero condicionamiento externo y extrínseco al mismo hombre? En virtud de una teología de la religión podríamos incluso preguntar: ¿es posible que para quienes nos reconocemos en distintas tradiciones religiosas el ejercicio de la libertad sea algo más que la mera reivindicación de los propios derechos?; ¿bajo qué condiciones la afirmación de la propia libertad puede ser también el reconocimiento de la libertad de los otros?; ¡cómo en el ejercicio de la libertad la distinción entre creyentes y no creyentes se desdibuja en favor de una común vocación?

A nuestro entender, el Concilio Vaticano II nos ofrece una pista muy importante para al menos esbozar una respuesta a preguntas como las anteriores. En efecto, pensamos que una de las expresiones mayores del giro soteriológico en la teología de la religión consiste el postulado de la libertad de conciencia ${ }^{25}$. En efecto, según el Vaticano II la conciencia es

"como el núcleo más secreto y el sagrario del hombre, en el que este se siente a solas con Dios, cuya voz resuena en el recinto más íntimo de aquella. Es la conciencia la que de modo admirable da a conocer esa ley, cuyo cumplimiento consiste en el amor de Dios y del prójimo. La fidelidad a esta conciencia une a los cristianos con los demás hombres para buscar la verdad y resolver con acierto los numerosos problemas morales que se presentan al individuo y la sociedad" (GS 16).

Y, a continuación, la misma GS afirma:

"La dignidad humana requiere, por tanto, que el hombre actúe según su conciencia y libre elección, es decir, movido e inducido por convicción interna personal y no bajo la presión de un ciego impulso interior o la mera coacción externa” (GS 17).

25 En el Concilio Vaticano el concepto "conscientia" se encuentra en 50 números y casi la mitad de ellos (23) pertenecen a Gaudium et Spes. 
Por su parte, en Lumen Gentium 16 la posibilidad universal de la salvación se establece desde dos líneas de argumentación fundamental. Primero, en base a los textos de Hech 17, 25-28 y 1 Tim 2, 4- se enfatiza que la universalidad de la salvación es posible por la misma voluntad y acción de Dios: Dios quiere que todos los hombres se salven y a todos da todas las cosas. La segunda línea de argumentación, complementariamente, pone el acento en la acción del hombre, animada por la gracia: quien busca a Dios con sincero corazón y cumple con obras su voluntad también puede alcanzar la salvación eterna. Ahora bien, ¿`cómo el hombre puede llegar a conocer y cumplir la voluntad de Dios? Por "el juicio de la conciencia" y "la gracia". Por tanto, es el juicio de la conciencia el que permite a todos los hombres reconocer la voluntad de Dios y cumplirla con obras, según la ayuda de su gracia.

En la Declaración Dignitatis humanae, el Concilio proclama la libertad social y civil en materia religiosa, apelando a la conciencia creciente que el hombre ha ido adquiriendo de su dignidad y libertad (DH 1): “... en materia religiosa ni se obligue a nadie a obrar contra su conciencia ni se le impida que actúe conforme a ella en privado y en público" (DH $2)^{26}$. Esta Declaración, como explica Sesboüé, "nos hace asistir a un giro en la manera con que la Iglesia se concibe a sí misma, un giro cuyos efectos van más allá de las circunstancias, dadas sus consecuencias doctrinales y pastorales"27. Doctrinalmente, esta Declaración representa un nuevo modo del quehacer dogmático: no solo deduce sus afirmaciones desde la tradición, sino que también desde la misma historia, desde los profundos anhelos de las personas y de los pueblos. Y en el "plano doctrinal, la Iglesia deja de considerar a la humanidad, católica o no, como un pueblo de menores que necesitan vivir bajo su tutela y conducidos con firmeza hacia la verdad a través de protecciones sociales fuertes" 28 .

La conciencia, como lo había explicado Newman 90 años antes de Gaudium et Spes ${ }^{29}$,

26 P. PAVAN, «Erklärung über die Religionsfreiheit. Einleitung und Kommentar», en Lexikon für Theologie und Kirche (Herder, Freiburg - Basel - Wien) 1987, 703-748.

27 B. SesBoüé, «La Iglesia católica y «los otros»: La libertad religiosa y las religiones no cristianas», en B. Sesboüé - C. Theobald (dirs.), Historia de los dogmas, IV (Secretariado Trinitario, Salamanca 1995) 439-469, 453.

29 Se ha afirmado que Newman es un precursor de la idea de conciencia desarrollada por el Vaticano II, especialmente de GS 15 y de NA. Así, H. Geissler Coscien- 
"no es una especie de egoísmo previsor ni un deseo de ser coherente con uno mismo; es un mensajero de Dios, que tanto en la naturaleza como en la gracia nos habla desde detrás de un velo y nos enseña y rige mediante sus representantes. La conciencia es el más genuino Vicario de Cristo, un profeta en sus mensajes, con autoridad perentoria como la de un Rey; un Sumo Sacerdote en sus bendiciones y anatemas. Aunque el eterno sacerdocio dejara de existir en la Iglesia, en la conciencia permanecería el principio sacerdotal y en ella tendría su poder"30.

Es así que "desde Newman y Kierkegaard la conciencia se sitúa con nueva urgencia al centro de la antropología cristiana"31.

El apelativo a la conciencia, y más expresamente a la libertad de conciencia, pudiera encubrir la voluntad inconfesada de vivir desde la sola subjetividad individual, desconociendo los nexos de la misma conciencia con la cultura, el mundo y Dios, como denunciaba el mismo New$\operatorname{man}^{32}$. Pero para el Vaticano II la conciencia no es una subjetividad individual, una mismidad autorreferida o una interioridad meramente pasiva. Por el contrario, la conciencia es intersubjetiva, es relación a Dios y al prójimo, es la libertad que decide y actúa a favor de la verdad y del bien de las personas y de la sociedad. La afirmación del hombre, de su conciencia, no implica el rechazo de Dios. La voz de Dios no acalla la voz del hombre, ni la voz del hombre acalla la de Dios. Por el contrario, como lo ha mostrado M. L. González a partir del pensamiento de J. H. Newman, "la obediencia a la conciencia moral es condición de posibilidad fundamental para el despliegue de la dimensión religiosa del hombre"33. La conciencia es lugar de la mutua escucha, el lugar donde

za e verita'nel drama della storia della savezaa secondo il pensero di John Henry Newman, en "Folia Theologica", 5 (1994) 115-117; J. Morales, Newman ante lo invisible, en Carta al Duque de Norfolk, Rialp, Madrid 1996, p.19 M. L. GonZÁLEZ FIGARI, La función de la obediencia a la conciencia moral en el despliegue de la dimensión religiosa del hombre a la luz del pensamiento de J.H. Newman, Facultad de Teología - Pontificia Universidad Católica de Chile, Santiago 2010.

30 J. H. Newman, Carta al Duque de Norfolk: sobre el desarrollo de la doctrina cristiana (Rialp, Madrid 1996) 73-74.

31 J. Ratzinger, «Pastorale Konstitution über die Kirche in der Welt von heute: Kommentar zum I.Kapitel», en Lexikon für Theologie und Kirche (Herder, Freiburg - Basel - Wien 1986) 328.

32 J. H. Newman, Carta al Duque de Norfolk, 75-76.

33 M. L. GONZÁLEZ FigARI, La función de la obediencia a la conciencia moral en el despliegue de la dimensión religiosa del hombre a la luz del pensamiento de J. H. Newman, 7. 
las voces de Dios y del hombre se compenetran, el lugar donde ellas se funden. Y porque así sucede, entonces la conciencia humana es apertura a la totalidad de la existencia, a los demás, a la sociedad. La condición intersubjetiva y social de la conciencia no es un momento segundo, un paso que se siga a un momento interior necesario. La conciencia es dónde el hombre se encuentra, a la vez, consigo mismo, con Dios y con los demás. Obviamente, no hablamos de una simultaneidad cronológica, sino de una constitución ontológica de la conciencia. Ella es siempre en esa apertura radical en la que fue llamada a la vida y el $\operatorname{ser}^{34}$.

La libertad y su real ejercicio en la Iglesia, enseña el Vaticano II, está indisolublemente asociada a la caridad y, así, se podrá manifestar más plenamente la auténtica catolicidad y apostolicidad de la Iglesia (cf. UR 4). Es la misma conciencia la que urge a la caridad. Ella nos permite reconocer al "prójimo como otro yo" (GS 27), a quien el hambriento interpela "recordando la palabra del Señor: Cuantas veces hicisteis eso a uno de estos hermanos menores, a mí me lo hicisteis (Mt 25, 40)" (GS 27). La conciencia es la capacidad para reconocer al otro, para comprender la propia existencia indisolublemente asociada a la vida de los demás, para acoger el llamado a la solidaridad que el Señor nos hace en los más pobres. La conciencia es conciencia social, es conciencia del deber tanto respecto a sí mismo como respecto a los varios grupos a los que pertenecemos (cf. GS 31). De este modo, la misma libertad religiosa alcanza su fondo más entrañable y emerge desde la conciencia no como la mera posibilidad formal - por cierto necesaria- de adherir a una u otra confesión religiosa, sino como la respuesta al sufrimiento y el dolor de millones de hombres y mujeres que reclaman de nuestra solidaridad, que nos interpelan a construir un mundo más justo y fraterno. Por ello, a la conciencia cristiana no le pueden ser indiferentes las injusticias entre los hombres y entre los pueblos. Como lo expresaran los obispos en Medellín, los "angustiosos problemas" que marcan la realidad en América Latina "hieren la conciencia cristiana" (Mensaje, Intr.).

34 Como explica Newman, "el Ser supremo es lo que en lenguaje humano llamamos un ser ético. La justicia, la verdad, sabiduría, santidad, benevolencia y misericordia son características eternas de su naturaleza, y la ley de su ser; ley que es idéntica a Él mismo. Cuando se hizo Creador, implantó esta ley -que es Él mismo- en la inteligencia de sus creaturas racionales" J. H. Newman, Carta al Duque de Norfolk, 73. 
Al destacar la centralidad de la libertad y de la conciencia, el Concilio está justamente afirmando que la gracia no acontece como imposición externa, sino que por la acogida libre del hombre, por su acción a favor de la verdad y del amor. La misma voluntad salvífica universal de Dios requiere que los hombres la reciban también "plena y conscientemente" (AG 7), lo cual implica reconocerla en el mismo hombre como espíri$\mathrm{tu}^{35}$. Como comenta R. Polanco,

"no podemos hablar de un acto verdaderamente humano que no sea, por eso mismo, consciente y libre. De allí que si bien la salvación universal traída por Cristo es acogida por cada hombre de forma consciente a partir de cada acto de bondad y verdad que realice a modo humano, con todo, por ser una acción movida por la gracia invisible de Cristo y la acción secreta del Espíritu Santo, igualmente cada acto está pidiendo una explicitación de esa relación con Dios que se establece con aquel mismo acto de bondad y verdad, para alcanzar así una acogida más plena y absolutamente definitiva del reino de Dios" ${ }^{36}$.

En este sentido, se puede afirmar que la experiencia implícita de salvación en la historia, queda igualmente remitida a la explicitación escatológica del reinado de Dios que acontecerá al final de los tiempos. La teología de la religiones deberá contribuir al "objetivo de formular una definición de la relación entre la pretensión de verdad escatológica y la estructura histórica de la revelación y también entre el condicionamiento histórico y sociológico del acceso y su pretensión y su contenido personal”37.

\section{EL GIRO SOTERIOLÓGICO COMO BÚSQUEDA DIALOGAL DE LA VERDAD}

El diálogo interreligioso se ha comprendido como "como método y medio para un conocimiento y enriquecimiento recíproco" (RM: 55). Esta breve caracterización indica una doble predisposición: a conocerse y a

35 Como afirma K. Rahner, "la gracia es una comunicación de sí mismo hecha por Dios al hombre. Esta comunicación es la base en que reposa la revelación y a la vez el fin último de la misma. Pero de aquí resulta que la revelación, sin perjuicio de su libre espontaneidad, es algo interior al ser histórico concreto del hombre, algo interno como la gracia misma -en cuanto comunicación divinizante de Dios- puede, y en definitiva debe, ser realmente en el hombre entendido como espíritu, sin que por ello pierda nada de su sobrenaturalidad y divinidad" K. RAHnER, Oyente de la palabra. Fundamentos para una filosofía de la religión, Herder, Barcelona 1967) 98.

36 R. Polanco, "La Iglesia y la universalidad de la salvación en el cristianismo», 428.

37 G. L. Müller, Dogmática. Teoría y práctica de la teología (Herder, Barcelona 1998) 13 . 
dejarse enriquecer por los otros. Ninguna de estas actitudes es obvia. Podríamos partir por el hecho mayor: del mutuo desconocimiento, los prejuicios, las distancias, e incluso de las odiosidades, que han incluido la destrucción y la muerte. En nuestro mismo contexto latinoamericano, la Asamblea de Obispos en Santo Domingo, destacaron "la importancia de profundizar un diálogo con las religiones no cristianas presentes en nuestro continente, particularmente las indígenas y afroamericanas, durante mucho tiempo ignoradas o marginadas" (n.137).

Históricamente, en las religiones ha primado la autosuficiencia: cada una de ellas considera poseer todo lo necesario para la salvación, no requiere de los demás, los demás no pueden enriquecer la propia experiencia del misterio único y trascendente. En los hechos, las religiones han sido muchas veces "factores de división y de conflicto entre los pueblos" ${ }^{38}$. De aquí que un diálogo interreligioso que aspire al mutuo conocimiento y enriquecimiento, puede ser un signo promisorio de un giro efectivamente salvífico: nos liberaría de la ignorancia y los prejuicios, de la arrogancia y autosuficiencia, de la vanidad y la soberbia. Pero, sobre todo, este diálogo podría representar una efectiva contribución de las religiones a la justicia y la paz entre las naciones. En esta perspectiva, nos parece importante el aporte de Puebla cuando pone la cuestión del diálogo entre las religiones y con los no creyentes claramente en una perspectiva soteriológica. En efecto, los obispos hacen un llamado a "incrementar el diálogo ecuménico entre las religiones y con los no creyentes con miras a la comunidad, buscando áreas de participación para el anuncio universal de la salvación" (Puebla, n. 1096). El diálogo queda bajo el signo y el imperativo de la comunión y salvación universal de Dios.

Es así que el diálogo con las demás religiones tiene un motivo y fundamento propiamente teológico y, por ello, soteriológico. Como lo expresara Juan Pablo II, este diálogo "es exigido por el profundo respeto hacia todo lo que en el hombre ha obrado el Espíritu, que «sopla donde quiere» (Jn 3, 8) (cf. RH: 12. 279). Con ello la Iglesia trata de descubrir las «semillas de la Palabra» (cf Ad gentes, 11.15), el «destello de aquella Verdad que ilumina a todos los hombres» (NA, 2), semillas y destellos que se encuentran en las personas y en las tradiciones religiosas de la humanidad. El diálogo se funda en la esperanza y la caridad, y dará frutos en el Espíritu. Las otras religiones constituyen un desafío positivo para

38 Comisión Teológica Internacional, «El cristianismo y las religiones», 2. 
la Iglesia de hoy; en efecto, la estimulan tanto a descubrir y a conocer los signos de la presencia de Cristo y de la acción del Espíritu, como a profundizar la propia identidad y a testimoniar la integridad de la Revelación, de la que es depositaria para el bien de todos" (RM: 56).

La valoración teológica del diálogo implica valorar al otro en su alteridad, en su diferencia, en su mismidad. En lo que el otro es, radica la posibilidad de reconocer los signos de la presencia del Espíritu, no en la nivelación ramplona de la diversidad de las religiones. Esto implica, por cierto, tomarse también en serio a sí mismo. El otro también tiene derecho a conocer nuestra identidad, el sentido hondo que anima nuestra esperanza y nuestra caridad. No es contrario a la humildad manifestar a los demás aquello que somos y esperamos. Si no lo hiciéramos, difícilmente podría producirse un real encuentro, un verdadero y mutuo enriquecimiento.

En la perspectiva anterior, pensamos que una teología de la religión -si quiere seguir siendo efectivamente teología- ${ }^{39}$, no puede abandonar lo que se ha denominado el "principio dogmático", el punto de inserción en la propia experiencia creyente, los criterios propiamente teológicos que informan el pensamiento ${ }^{40}$. A diferencia de una filosofía de la religión, la teología de la religión es una ciencia normativa que formula sus juicios de valor no solo a la luz de la razón, sino que también a la luz de la revelación de Dios en Cristo, acogida y transmitida por la comunidad de los creyentes ${ }^{41}$. Un giro efectivamente soteriológico no busca un punto neutral de observación de todas las religiones, para descubrir lo que en cada una de ellas hay de verdad y así, a partir de trazos, eventualmente componer un todo. Más bien, la perspectiva soteriológica supone la propia experiencia personal y social de la fe; es desde esta experiencia -nunca fuera de ella- desde donde podremos percibir críticamente lo que hay de verdad y falsedad, tanto en nosotros mismos como en otros; es en la experiencia de la presencia del reinado de Dios en medio nuestro, que podremos apreciar la realización de la justicia de Dios más allá de nosotros mismos. En definitiva, es el mismo giro soteriológico el que posibilita una nueva mirada y actitud hacia las demás religiones, el que nos impulsa al diálogo, el que nos hace salir de nosotros mismos para ir

\footnotetext{
39 M. SECKLER, «Der theologische Begriff der Religion», 133.

40 Cf. P. GISEL, La théologie face aux sciences religieuses.

41 M. Dhavamony, «Religión: Teología de las religiones», 1219.
} 
al encuentro de los otros. Ciertamente, el fenómeno religioso puede ser observado desde diversas perspectivas; es legítimo y necesario reconocer esta pluralidad de miradas. Pero, justamente, esa pluralidad reclama la diferencia y, la misma diferencia, la identidad: una identidad que no se constituye por la suma de partes o la igualación de lo diverso, sino en el reconocimiento de sí y de los demás para concordar en un mismo movimiento que tiene como fuente y destino al único Dios.

En un auténtico diálogo interreligioso la pregunta por la verdad no puede ser una pregunta por la adecuación de las demás religiones al culto, la doctrina y la moral católica. La búsqueda de la verdad supone el auténtico reconocimiento del otro y de las posibilidades de que en él se manifieste el Ser como verdad, belleza y bien. En esta perspectiva adquiere particular importancia la Declaración conciliar Nostra Aetate (28 octubre 1965) por cuanto en ella, luego de situar las relaciones de la Iglesia con las religiones no cristianas en el trasfondo antropológicosocial de los "vínculos", la "unidad", la "caridad", entre otros (cf. NA, 1), afirma que

"la Iglesia católica nada rechaza de lo que en estas religiones hay de verdadero y santo. Considera con sincero respeto los modos de obrar y de vivir, los preceptos y doctrinas, que, aunque discrepen en muchos puntos de lo que ella profesa y enseña, no pocas veces reflejan un destello de aquella Verdad que ilumina a todos los hombres" (NA 2).

Aunque pudiéramos desear menos restricciones ["nada rechaza" -nihil reicit; "discrepen en muchos puntos"- in multis discrepent], debemos reconocer que en esta Declaración -que el año 1960 partió como un texto solicitado por Juan XXIII sobre los judíos y que luego no se sabía mucho dónde ubicar ${ }^{42}-$, por

"primera vez en la historia un Concilio habla con aprecio de las percepciones que los hombres, familias y pueblos tienen del Absoluto; por primera vez ella se inclina con respeto ante lo verdadero y santo en las otras religiones como obras del único Dios vivo. Del mismo modo, es la primera vez que la Iglesia asume la perspectiva paulina respecto del mysterium de Israel. La Declaración es una confesión de

42 Cf. R. A. Siebenrock, «Theologischer Kommentar zur Erklärung über die Haltung der Kirche zu den christlichen Religionen Nostra aetate», en Herders Theologischer Kommentar zum Zweiten Vatikanischen Konzil (Herder 2005) 633 y ss. 
la Iglesia de la presencia omnipresente de la gracia y de su eficacia en la muchas religiones de la humanidad" ${ }^{3}$.

Este giro en la mirada hacia las demás religiones -y que Welte comprende como "un quiebre epocal” ${ }^{4}$-, posibilita un diálogo que va más allá del solo reconocimiento respetuoso del otro, que busca la presencia salvífica de Dios fuera de las propias fronteras, que reconoce la única verdad en sus múltiples manifestaciones. Sin duda, este giro está fuertemente condicionado por las condiciones históricas y religiosas de la época: Nostra Aetate. Sin embargo, el solo imperativo epocal no explica suficientemente este hecho inédito de la historia eclesial. La raíz más honda del giro en la mirada es estrictamente teológica: la acción libre y gratuita de Dios. Como lo expresa Welte, "no podemos seguir comprendiendo nuestro cristianismo sin considerar seriamente las demás religiones, esto es sin considerarlas respecto de Dios y su anuncio de salvación” ${ }^{3}$.

La pregunta por la verdad, implica reconocer la radical ambigüedad de toda experiencia humana y, especialmente, de la religión; por cuanto esta, revestida del poder de lo santo, puede más fácilmente encubrir los oscuros propósitos de la voluntad y los más falaces argumentos de la inteligencia. La cuestión de la verdad de la religión -en sus diferentes formas-, y la de su perversión -en sus diferentes formas-, están estrechamente relacionadas. La teología no puede pensar una desconociendo la otra ${ }^{46}$. En el sentido de K. Barth cuando hablamos de la verdad de la religión, debemos ser conscientes del pecado, de la radical precariedad y debilidad, que amenaza toda realización histórica de la respuesta creyente del hombre a Dios, de la posibilidad que en ella se encubra la más cínica incredulidad, de que ella no sea más que una fábrica idolorum ${ }^{47}$. En efecto, "solo podemos hablar de «verdadera» religión, así como ha-

43 J. Oesterreicher, «Erklärung über das Verhältnis der Kirche zu den nichtchristlichen Religionen. Kommentierende Einleitung», en Lexikon für Theologie und Kirche (Herder, Freiburg - Basel - Wien 1986) 406. En un sentido semejante se expresa también R. A. Siebenrock, en el comentario de la Herder. Cf. R. A. Siebenrock, «Theologischer Kommentar zur Erklärung über die Haltung der Kirche zu den christlichen Religionen Nostra aetate», 666.

44 “... ein epochaler Durchbruch” B. Welte, «Christentum und Religionen der Welt», 75.

45 Ibid, 72.

46 Cf. P. Gisel, La théologie face aux sciences religieuses, 279-280.

47 K. BARTH, Kirchliche Dogmatik. I/2: Die Lehre vom Wort Gottes, I/2 (Evangelischer Verlag A.G., Zollikon-Zürich 1960) 355. 
blamos de un "pecador justificado»"48; la religión solo puede llegar a ser verdadera si ella es resultado de la revelación de Dios, de su gracia y de su autocomunicación a los hombres; por el contrario, cuando se eroga desde sí la posibilidad de ser salvación para los hombres ella es solo incredulidad y falsedad ${ }^{49}$. En este sentido, la teología de la religión puede contribuir a una auténtica relativización del cristianismo; no por la vía de una homologación y nivelación con las otras religiones, sino que situándolo -junto a las demás religiones- de cara a la fe desde la cual ha sido constituido por la gracia, a la fe que le permite reconocer su constante necesidad de conversión, a la fe que vive de la gracia y misericordia de Dios $^{50}$.

La teología, en este sentido, debe posibilitar una comprensión crítica de la religión, especialmente de las propias formas históricas del $\operatorname{creer}^{51}$. Es constitutiva de esta forma del creer, el que

"solo Dios, y no el conocimiento que de él tenemos, es absoluto. En cierto sentido, no hay ninguna verdad totalmente verdadera, ya que todas ellas dejan sombras a su alrededor, que por otra parte son necesarias para su manifestación. Nos lo confirma la regla teológica de la analogía, precisando incluso que, en el conocimiento que nos permite alcanzar, la desemejanza es más importante que la semejanza [...] En el fondo, ningún discurso y ninguna revelación lo dicen todo, aunque sean verdaderos. El cristianismo no pretende nada más; lo que hace es orientarnos hacia una escatología, que la única que puede saciarnos" 52 .

Como enseñó el mismo Vaticano II, es necesario distinguir el depósito de la fe de sus posibles formulaciones (GS 62); es necesario, afirma Barth, reconocer la primacía a Dios y su revelación respecto de cualquier

\footnotetext{
48 Ibid, 356.
}

49 Barth reconoce en el cristianismo la verdadera religión, pero solo si permanecemos en la analogía del "pecador justificado", puesto que es más que una analogía, corresponde a la misma cosa: "In dem wir streng und genau in dieser Analogie bleiben -und sie ist mehr al eine Analogie, sie ist in umfassendem Sinn die Sache selbst, um die es hier geht- dürfen wir nicht zögern, es auszusprechen: die christliche Religion ist die wahre Religion" Ibid, 357.

50 Cf. Ibid, 362 y ss.

51 Cf. R. Schaeffler, "Die Kritik der Religion», in W. Kern et al. (dirs.), Handbuch der Fundamentaltheologie (Francke, Tübingen// Basel 2000) 85-99.

52 A. Gesché, El destino: Dios para pensar III, 191-192. 
intento de la religión -incluido el cristianismo- por erigirse a sí mismo como salvación del hombre ${ }^{53}$.

Es así que la cuestión de la verdad no sea una cuestión distinta, o al margen, de la pregunta por la actuación salvífica de las religiones. El giro soteriológico, en la perspectiva del Vaticano II, implica para la comunidad de los creyentes desear "solo una cosa: continuar, bajo la guía del Espíritu Santo, la obra misma de Cristo, quien vino al mundo para dar testimonio de la verdad $(\mathrm{Jn} 18,37)$, para salvar y no para juzgar, para servir y no para ser servido (Jn 3, 17; Mt 20, 28; Mc 10, 455" (GS 3). La verdad aquí no es un "discurso", una teoría, un "mensaje"; más bien, en el seguimiento de Jesús y por la gracia del Espíritu Santo, la verdad acontece en el testimonio de la vida entregada, en la acción salvífica a favor de los pobres y pecadores, en quien se hace siervo de los demás. Por ello, dirá Nostra Aetate, "la Iglesia reprueba como ajena al espíritu de Cristo cualquier discriminación o vejación realizada por motivos de raza o color, de condición o religión" (NA 5). Como lo expresa Siebenrock comentando este pasaje de NA, "la pregunta por la passio humana es el lugar donde todos los hombres pueden comprobar el anuncio de la fe cristiana y la verdad de las religiones [...] La verdad de Dios se demuestra siempre en el encuentro con los demás" ${ }^{54}$.

Si se asume radicalmente el giro soteriológico, la cuestión de la verdad queda indisolublemente unida a la caridad y viceversa. Como enseñaba Benedicto XVI, especialmente en nuestros tiempos, constatamos

53 En principio, todas las religiones están bajo el mismo juicio: "la religión es incredulidad". Y explica: "Dieses Urteil bedeutet aber konkret: unsere ganze Betätigung unseres Glaubens: unsere christlichen Vorstellungen von Gott und den göttlichen Dingen, unsere christliche Theologie, unsere christlichen Gottesdienste, unsere christlichen Gemeinschafts- und Ordnungsformen, unsere christliche Moral, Poesie und Kunst, unsere Versuche individueller und sozialer christlicher Lebensgestaltung, unsere christliche Strategie und Taktik zugunsten unserer christlichen Sache, kurz, unser Christentum, sofern es eben unser Christentum, das von uns unternommene und diesen und jenen Nah- und Fernzielen entgegengeführte Menschenwerk ist, das als solches mit dem Menschenwerk anderer Religionen auf einer Ebene sichtbar wird -dieses Ganze als solches und in seinen Einzelheiten ist gerade nicht das, was es sein möchte und zu sein vorgibt: ein Werk des Glaubens und also des Gehorsams gegen Gottes Offenbarung" K. BARTH, Kirchliche Dogmatik. I/2: Die Lehre vom Wort Gottes, 358.

54 R. A. Siebenrock, «Die Wahrheit der Religionen und die Fülle der Selbstmitteilung Gottes in Jesus Christus», en P. Hünermann - B. J. Hilberath (dirs.), Herders Theologischer Kommentar zum Zweiten Vatikanischen Konzil (Verlag Herder 2006) 131. 
"la necesidad de unir no solo la caridad con la verdad, en el sentido señalado por San Pablo de la «veritas in caritate» (Ef 4, 15), sino también en el sentido, inverso y complementario, de "caritas in veritate». Se ha de buscar, encontrar y expresar la verdad en la «economía» de la caridad, pero, a su vez, se ha de entender, valorar y practicar la caridad a la luz de la verdad. De este modo, no solo prestaremos un servicio a la caridad, iluminada por la verdad, sino que contribuiremos a dar fuerza a la verdad, mostrando su capacidad de autentificar y persuadir en la concreción de la vida social" (Caritas in veritate, 2).

Es por ello que la búsqueda de "lo razonable" no basta en el testimonio de la fe. Efectivamente, "lo que permite el entendimiento entre los seres humanos situados en espacios y tiempos distintos -y condicionados radicalmente por ello- no es la fe, sino la razón (no en el sentido racionalista del término, sino en su significado de razonable)" 55 . La razonabilidad es efectivamente una condición necesaria para el entendimiento entre los hombres, pero no es una condición suficiente. Solo el amor basta. Solo el amor es creíble ${ }^{56}$. Es este el desplazamiento que sugerimos a la teología de las religiones: contribuir positivamente a que las distintas tradiciones religiosas de la humanidad contribuyan eficazmente a una auténtica una civilización del amor.

La verdad de cualquier religión no se juega -simplemente- por la declaración de sus intenciones, sino que -en último término- por su capacidad histórica para ser fuente de salvación. Y ello se establece empíricamente. No hay otro camino posible: "los cojos ven, los...". Es cierto que la salvación -el reinado de Dios- no se agota en estos signos externos, pero también es cierto que no se da sin ellos. Es cierto que la salvación no se reduce a sus realizaciones históricas y que ella es siempre de carácter escatológico; sin embargo, la escatología no se puede argüir como excusa de la historicidad sino como anuncio gozoso de que la salvación plena y definitiva ya se ha iniciado en los hechos y palabras de Jesús de Nazareth, en la comunidad de sus discípulos y discípulas. ¿Y quiénes son estos discípulos y discípulas? De nuevo el criterio es de carácter empírico: "no todo el que diga Señor, Señor entrará en el reino de los cielos, sino el que hace la voluntad de mi Padre” (Mt 7, 21).

55 A. BENTUÉ, Jesucristo en el pluralismo religioso, 19 (subrayado nuestro).

56 Cf. H. U. von Balthasar, Solo el amor es digno de fe (Sígueme, Salamanca 1971). 
En esta perspectiva, considero que es el mismo "principio dogmático" el que lleva a que la teología no sea una ciencia especulativa de principios filosóficos y teológicos abstractos, desde los cuales se extraen postulados prácticos, sino que un pensamiento crítico del acontecimiento de la salvación en la historia. En la perspectiva de Gaudium et Spes (nn. 4 y 11), el giro soteriológico implica para la teología abandonar un método meramente inductivo y asumir creativamente categorías y métodos que le permitan constituirse eficazmente como una teología de la historia. Como lo ha expresado C. Schickendantz:

"la obediencia a la autoridad de los que sufren, las víctimas, y la irrupción del pobre y su correlativa opción preferencial, constituyen lugares, sujetos emergentes y comunidades lingüísticas concretas, desde donde fluye una lucidez, una determinada capacidad de ver, que, conforme a la providencia de Dios, no proviene de otra fuente; dichas perspectivas, una vez asumidas, capacitan para pensar de otra manera" ${ }^{\prime \prime}$.

Es el mismo giro soteriológico el que invita a volver la mirada; y no hacia donde cada uno quiera o más le guste; sino que hacia donde Dios, movido de amor, ha querido volcar toda su existencia en Cristo: hacia los pobres, hacia cuantos se les niega la dignidad y la vida. Este es el principio dogmático por excelencia, respecto del cual debe articularse una teología cristiana de las religiones.

\section{CONCLUSIONES}

El giro soteriológico en la teología de la religión debe llevarnos a la humildad: humildad para conocer, para aprender, para reconocer la acción del Espíritu Santo fuera de los márgenes visibles de Iglesia católica (LG 16; GS 22). La humildad no es una conducta psíquica, ni una disposición del ánimo -al menos no principalmente-, sino que una actitud espiritual $y$, propiamente, una virtud que informa nuestra acción. Ella se funda en la convicción de que la salvación es de Dios; que hemos sido escogidos inmerecidamente para ser testigos de su Evangelio; que de lo que se trata -de una vez por todas- no es de nosotros mismos, de nuestros mezquinos

57 «Hacia un nuevo método teológico a partir de Gaudium et Spes. Una elipse con dos focos", in Teología de los signos de los tiempos latinoamericanos. Horizontes, criterios y métodos (Colección Teología de los tiempos 11, Ediciones Universidad Alberto Hurtado, Santiago 2013), 53-87. 
intereses, de nuestra frágil institucionalidad, sino que de su reinado en medio nuestro. Si esta humildad nos lleva a experimentar alguna crisis de identidad, de pertenencia o de misión, bienvenida sea la crisis. Ella nos permitirá despojarnos de falsas seguridades, nos permitirá asemejarnos a nuestro Señor y Maestro, quien se despojó de su misma condición divina para que Dios llegara a ser todo en todos (1 Cor 15, 28).

El giro soteriológico del que hemos hablado aquí debe llevar a acciones concretas en la vida de la Iglesia y de la teología. El giro no puede ser meramente declarativo, teórico, especulativo. Debe estar en estrecha relación tanto con nuestra teoría como con nuestra práctica. Por ello, la teología de la religión deberá estar atenta a diversos ámbitos y niveles en los que hoy se pueda desarrollar un diálogo entre las religiones: en el intercambio entre expertos de las tradiciones religiosas o representantes oficiales de las mismas; en la colaboración para el desarrollo integral y la promoción de los valores religiosos; en la comunicación de las respectivas experiencias espirituales; en el testimonio de los creyentes de las diversas religiones de los propios valores humanos y espirituales, y su contribución para edificar una sociedad más justa y fraterna ${ }^{58}$.

Pensamos que la pregunta, o "cuestión de fondo", en la teología de las religiones es efectivamente soteriológica: ¿son las religiones mediaciones de salvación para los pueblos? Pareciera, sin embargo, que las teologías de la religión no hubieran estado del todo a la altura de la pregunta. En efecto, la pregunta contiene tres elementos que se distinguen nítidamente: las religiones, la salvación, los pueblos. En la pregunta, estos elementos no se yuxtaponen sino que se unen según una causa final, según un "ser-para". El supuesto fundamental de la pregunta es que las religiones son propter nostram salutem. No solo se reconoce un nexo necesario entre religión y salvación, sino que ese nexo se establece concretamente y queda determinado por el sentido que él pueda tener para las personas, para los pueblos y culturas. Es decir, la cuestión de fondo es efectivamente soteriológica, es la cuestión de la pro existencia, en este caso de la religión.

Pero las respuestas parecieran haber desplazado la pregunta desde el "ser-para", al "ser-en-sí"; y, por supuesto, en la pasada se ha perdido la fuerza soteriológica contenida en la pregunta; o, al menos, se desdibuja y queda como un implicado. En todos los modelos de los que hemos

58 Cf. RM 57. 
tratado, a lo más permanecen solo dos elementos: las religiones -en este caso el cristianismo- y la salvación. Si tomamos cualquiera de los tres modelos (eclesiocentrismo exlcusivista, cristocentrismo inclusivista o teocentrismo pluralista), en ninguno de ellos se explicita aquel "ser-para” que contiene la pregunta por el carácter salvífico de las religiones. Sin embargo, desde la tradición judeo-cristiana, ni la Iglesia, ni Cristo, ni Dios - guardando las diferencias- son un "en-sî" o un "para-sí". Por ello, en rigor, el centro no es la Iglesia, tampoco Cristo, ni menos Dios. Más radicalmente aún: habría que decir que aquí no se trata de establecer un centro, puesto que -definitivamente- no hay centro, sino relación: y la relación solo se dice como donación, como entrega de sí, como un "ser-para". Este es, a nuestro juicio, el déficit principal de una teología de la religión que no se articula trinitariamente: finalmente, ella no se entiende como relación ni diálogo, ni tampoco como solidaridad ni comunión ${ }^{59}$. El giro soteriológico en la teología de las religiones no puede ser sino conversión al Dios que es amor y que se ha hecho solidario con la historia de dolor y sufrimiento de los hombres, que ha animado sus búsquedas de justicia y de libertad, y que en su Espíritu ha regalado a toda carne la esperanza inclaudicable de un cielo y de una tierra nueva (Is 65, 17; Ap 21, 1).

59 Cf. R. Schreiter, «Hindernisse und Leitlinien für die Mission und den Dialog mit den Religionen», 448. Para una teología de la religión en perspectiva trinitaria, cf. S. M. Heim, The depth of the riches: a Trinitarian theology of religious ends (Sacra doctrina, Eerdmans, Grand Rapids, Mich.) 2001. 
Resumen: En línea con el Vaticano II y una larga tradición profética, en este texto proponemos un giro propiamente soteriológico en la teología de las religiones, el que pensamos solo puede hacerse si nos volvemos a la pregunta por la verdad de la religión y, desde aquí, obtenemos algunos criterios que nos permitan discernir históricamente las posibilidades y obstáculos que las distintas religiones pueden ofrecer al resplandor de la gloria de Dios, que es la vida plena del hombre (Jn 10, 10). Pensamos que la teología de las religiones debe asumir una acuciante pregunta soteriológica: ¡son las religiones mediaciones de salvación para los pueblos? Una pregunta que no se resuelve en abstracto, sino que por la experiencia que los hombres y mujeres de nuestro tiempo puedan hacer de la caridad, de la libertad y de la verdad.

Palabras clave: Religión, Teología de la religión, Soteriología.

Abstract: This paper offers a soteriological turn -according to Vatican II and to a rich prophetic tradition - to the question on the salvific character of religions. This theology of religions starts with the issue of the truth of religions. Do they let

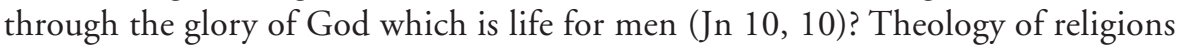
should presuppose a soteriological question: are religions instruments for the salvation of all men? The answer depends on the way people experience today charity, freedom and truth through religion.

Keywords: Religion, Theology of religion, Soteriology. 
